\title{
Pacific
}

Journal of

Mathematics

\section{ENERGY AND VOLUME OF VECTOR FIELDS ON SPHERICAL DOMAINS}

FAbiano G. B. BRito, ANDRÉ O. Gomes AND Giovanni S. Nunes 


\title{
ENERGY AND VOLUME OF VECTOR FIELDS ON SPHERICAL DOMAINS
}

\author{
Fabiano G. B. Brito, André O. Gomes and Giovanni S. Nunes
}

We present a "boundary version" for theorems about minimality of volume and energy functionals on a spherical domain of an odd-dimensional Euclidean sphere.

\section{Introduction}

Let $(M, g)$ be a closed, $n$-dimensional Riemannian manifold and $T^{1} M$ the unit tangent bundle of $M$ considered as a closed Riemannian manifold with the Sasaki metric. Let $X: M \rightarrow T^{1} M$ be a unit vector field defined on $M$, regarded as a smooth section of the unit tangent bundle $T^{1} M$. The volume of $X$ was defined in [Gluck and Ziller 1986] by vol $X:=\operatorname{vol} X(M)$, where vol $X(M)$ is the volume of the submanifold $X(M) \subset T^{1} M$. Using an orthonormal local frame $\left\{e_{1}, e_{2}, \ldots, e_{n-1}, e_{n}=X\right\}$, the volume of the unit vector field $X$ is given by

$$
\begin{aligned}
\operatorname{vol} X=\int_{M}\left(1+\sum_{a=1}^{n}\left\|\nabla_{e_{a}} X\right\|^{2}+\right. & \sum_{a<b} \\
& \left\|\nabla_{e_{a}} X \wedge \nabla_{e_{b}} X\right\|^{2}+\cdots \\
& \left.+\sum_{a_{1}<\cdots<a_{n-1}}\left\|\nabla_{e_{a_{1}}} X \wedge \cdots \wedge \nabla_{e_{a_{n-1}}} X\right\|^{2}\right)^{1 / 2} v_{M}(g)
\end{aligned}
$$

and the energy of the vector field $X$ is given by

$$
\mathscr{E}(X)=\frac{n}{2} \operatorname{vol} M+\frac{1}{2} \int_{M} \sum_{a=1}^{n}\left\|\nabla_{e_{a}} X\right\|^{2} v_{M}(g) .
$$

The Hopf vector fields on $\mathbb{S}^{2 k+1}$ are unit vector fields tangent to the classical Hopf fibration $\mathbb{S}^{1} \hookrightarrow \mathbb{S}^{2 k+1}$. The following theorems gives a characterization of Hopf flows as absolute minima of volume and energy functionals:

Theorem 1 [Gluck and Ziller 1986]. The unit vector fields of minimum volume on the sphere $\mathbb{S}^{3}$ are precisely the Hopf vector fields and no others.

Keywords: energy of vector fields, volume of vector fields, Hopf flow. 
Theorem 2 [Brito 2000]. The unit vector fields of minimum energy on the sphere $\mathbb{S}^{3}$ are precisely the Hopf vector fields and no others.

We prove in this paper the following boundary version for these theorems:

Theorem 3. Let $U$ be an open set of the $(2 k+1)$-dimensional unit sphere $\mathbb{S}^{2 k+1}$ and let $K \subset U$ be a connected $(2 k+1)$-submanifold with boundary of the sphere $\mathbb{S}^{2 k+1}$. Let $\vec{v}$ be an unit vector field on $U$ which coincides with a Hopfflow $H$ along the boundary of $K$. Then

$$
\mathscr{E}(\vec{v}) \geq\left(\frac{2 k+1}{2}+\frac{k}{2 k-1}\right) \operatorname{vol} K \quad \text { and } \quad \operatorname{vol} \vec{v} \geq \frac{4^{k}}{\left(\begin{array}{c}
2 k \\
k
\end{array}\right)} \operatorname{vol} K .
$$

(Other results for higher dimensions may be found in [Brito et al. 2004; Borrelli and Gil-Medrano 2006; Chacón et al. 2001].)

\section{Preliminaries}

Let $U \subset \mathbb{S}^{2 k+1}$ be an open set of the unit sphere and let $K \subset U$ be a connected $(2 k+1)$-submanifold with boundary of $\mathbb{S}^{2 k+1}$. Let $H$ be a Hopf vector field on $\mathbb{S}^{2 k+1}$ and let $\vec{v}$ be an unit vector field defined on $U$. We also consider the map $\varphi_{t}^{\vec{v}}: U \rightarrow \mathbb{S}^{2 k+1}\left(\sqrt{1+t^{2}}\right)$ given by $\varphi_{t}^{\vec{v}}(x)=x+t \vec{v}(x)$. This map was introduced in [Asimov 1978; Brito et al. 1981; Milnor 1978].

Lemma 4. For $t>0$ sufficiently small, the map $\varphi_{t}^{\vec{v}}$ is a diffeomorphism.

Proof. A simple application of the identity perturbation method.

From now on, we assume that $t>0$ is small enough so that the map $\varphi_{t}^{\vec{v}}$ is a diffeomorphism. In order to find the Jacobian matrix of $\varphi_{t}^{\vec{v}}$, we define the unit vector field $\vec{u}$ on $\varphi_{t}^{\vec{v}}(U) \subset \mathbb{S}^{2 k+1}\left(\sqrt{1+t^{2}}\right)$ by

$$
\vec{u}(x):=\frac{1}{\sqrt{1+t^{2}}} \vec{v}(x)-\frac{t}{\sqrt{1+t^{2}}} x .
$$

Using an adapted orthonormal frame $\left\{e_{1}, \ldots, e_{2 k}, \vec{v}\right\}$ on a neighborhood $V$ of $U$, we obtain an adapted orthonormal frame on $\varphi_{t}^{\vec{v}}(V)$ given by $\left\{\bar{e}_{1}, \ldots, \bar{e}_{2 k}, \vec{u}\right\}$, where $\bar{e}_{i}=e_{i}$ for all $i \in\{1, \ldots, 2 k\}$.

In this manner, we can write

$$
\begin{aligned}
d \varphi_{t}^{\vec{v}}\left(e_{1}\right) & =\left\langle d \varphi_{t}^{\vec{v}}\left(e_{1}\right), e_{1}\right\rangle e_{1}+\ldots+\left\langle d \varphi_{t}^{\vec{v}}\left(e_{1}\right), e_{2 k}\right\rangle e_{2 k}+\left\langle d \varphi_{t}^{\vec{v}}\left(e_{1}\right), \vec{u}\right\rangle \vec{u}, \\
d \varphi_{t}^{\vec{v}}\left(e_{2}\right) & =\left\langle d \varphi_{t}^{\vec{v}}\left(e_{2}\right), e_{1}\right\rangle e_{1}+\ldots+\left\langle d \varphi_{t}^{\vec{v}}\left(e_{2}\right), e_{2 k}\right\rangle e_{2 k}+\left\langle d \varphi_{t}^{\vec{v}}\left(e_{2}\right), \vec{u}\right\rangle \vec{u}, \\
& \vdots \\
d \varphi_{t}^{\vec{v}}\left(e_{2 k}\right) & =\left\langle d \varphi_{t}^{\vec{v}}\left(e_{2 k}\right), e_{1}\right\rangle e_{1}+\ldots+\left\langle d \varphi_{t}^{\vec{v}}\left(e_{2 k}\right), e_{2 k}\right\rangle e_{2 k}+\left\langle d \varphi_{t}^{\vec{v}}\left(e_{2 k}\right), \vec{u}\right\rangle \vec{u}, \\
d \varphi_{t}^{\vec{v}}(\vec{v}) & =\left\langle d \varphi_{t}^{\vec{v}}(\vec{v}), e_{1}\right\rangle e_{1}+\ldots+\left\langle d \varphi_{t}^{\vec{v}}(\vec{v}), e_{2 k}\right\rangle e_{2 k}+\left\langle d \varphi_{t}^{\vec{v}}(\vec{v}), \vec{u}\right\rangle \vec{u} .
\end{aligned}
$$


Now, by Gauss's equation for the trivial immersion $\mathbb{S}^{2 k+1} \hookrightarrow \mathbb{R}^{2 k+2}$, we have

$$
\tilde{\nabla}_{Y} \vec{v}=d \vec{v}(Y)=\nabla_{Y} \vec{v}-\langle\vec{v}, Y\rangle x
$$

for every vector field $Y$ on $\mathbb{S}^{2 k+1}$, and then

$$
\left\langle d \varphi_{t}^{\vec{v}}\left(e_{1}\right), e_{1}\right\rangle=\left\langle e_{1}+t d \vec{v}\left(e_{1}\right), e_{1}\right\rangle=1+t\left\langle\nabla_{e_{1}} \vec{v}, e_{1}\right\rangle
$$

Analogously, we can conclude that

$$
\begin{aligned}
\left\langle d \varphi_{t}^{\vec{v}}\left(e_{i}\right), e_{i}\right\rangle & =1+t\left\langle\nabla_{e_{i}} \vec{v}, e_{i}\right\rangle & & \text { for } i \in\{1, \ldots, 2 k\}, \\
\left\langle d \varphi_{t}^{\vec{v}}\left(e_{i}\right), e_{j}\right\rangle & =t\left\langle\nabla_{e_{i}} \vec{v}, e_{j}\right\rangle & & \text { for } i, j \in\{1, \ldots, 2 k\}, i \neq j, \\
\left\langle d \varphi_{t}^{\vec{v}}\left(e_{i}\right), \vec{u}\right\rangle & =0 & & \text { for } i \in\{1, \ldots, 2 k\}, \\
\left\langle d \varphi_{t}^{\vec{v}}(\vec{v}), \vec{u}\right\rangle & =\sqrt{1+t^{2}} . & &
\end{aligned}
$$

By employing the notation $h_{i j}(\vec{v}):=\left\langle\nabla_{e_{i}} \vec{v}, e_{j}\right\rangle$ (where $i, j \in\{1, \ldots, 2 k\}$ ), we can express the determinant of the Jacobian matrix of $\varphi_{t}^{\vec{v}}$ in the form

$$
\operatorname{det}\left(d \varphi_{t}^{\vec{v}}\right)=\sqrt{1+t^{2}}\left(1+\sum_{i=1}^{2 k} \sigma_{i}(\vec{v}) t^{2}\right)
$$

where, by definition, the functions $\sigma_{i}$ are the $i$-symmetric functions of the $h_{i j}$. For instance, if $k=1$, we have

$$
\begin{aligned}
& \sigma_{1}(\vec{v}):=h_{11}(\vec{v})+h_{22}(\vec{v}), \\
& \sigma_{2}(\vec{v}):=h_{11}(\vec{v}) h_{22}(\vec{v})-h_{12}(\vec{v}) h_{21}(\vec{v}) .
\end{aligned}
$$

\section{Proof of the Theorem}

The energy of the vector field $\vec{v}$ (on $K$ ) is given by

$$
\mathscr{E}(\vec{v}):=\frac{1}{2} \int_{K}\|d \vec{v}\|^{2}=\frac{2 k+1}{2} \operatorname{vol} K+\frac{1}{2} \int_{K}\|\nabla \vec{v}\|^{2}
$$

Using the notation above, we have

$$
\mathscr{E}(\vec{v})=\frac{2 k+1}{2} \operatorname{vol} K+\frac{1}{2} \int_{K}\left(\sum_{i, j=1}^{2 k}\left(h_{i j}(\vec{v})\right)^{2}+\sum_{i=1}^{2 k}\left\langle\nabla_{\vec{v}} \vec{v}, e_{i}\right\rangle^{2}\right)
$$

and then

$$
\mathscr{E}(\vec{v}) \geq \frac{2 k+1}{2} \operatorname{vol} K+\frac{1}{2} \int_{K} \sum_{i, j=1}^{2 k}\left(h_{i j}(\vec{v})\right)^{2}
$$


Now observe that

$$
\sum_{i<j}\left(h_{i i}-h_{j j}\right)^{2}=(2 k-1) \sum_{i} h_{i i}^{2}-2 \sum_{i<j} h_{i i} h_{j j}
$$

and

$$
\sum_{i<j}\left(h_{i j}+h_{j i}\right)^{2}=\sum_{i \neq j} h_{i j}^{2}+2 \sum_{i<j} h_{i j} h_{j i} .
$$

If we sum these last two equations, we get

$$
(2 k-1) \sum_{i} h_{i i}^{2}+\sum_{i \neq j} h_{i j}^{2} \geq 2 \sigma_{2}
$$

and then

$$
\sum_{i} h_{i i}^{2}+\frac{1}{2 k-1} \sum_{i \neq j} h_{i j}^{2} \geq \frac{2}{2 k-1} \sigma_{2}
$$

Also, we can write

$$
\sum_{i, j=1}^{2 k} h_{i j}^{2}=\sum_{i \neq j} h_{i j}^{2}+\sum_{i} h_{i i}^{2} \geq \sum_{i} h_{i i}^{2}+\frac{1}{2 k-1} \sum_{i \neq j} h_{i j}^{2}
$$

From this and (2), we obtain

$$
\sum_{i, j=1}^{2 k}\left(h_{i j}(\vec{v})\right)^{2} \geq \frac{2}{2 k-1} \sigma_{2}(\vec{v})
$$

But then, using inequality (1), we find that

$$
\mathscr{E}(\vec{v}) \geq \frac{2 k+1}{2} \operatorname{vol} K+\frac{1}{2 k-1} \int_{K} \sigma_{2}(\vec{v}) .
$$

On the other hand, by the change of variables theorem, we obtain

$$
\operatorname{vol} \varphi_{t}^{H}(K)=\int_{K} \sqrt{1+t^{2}}\left(1+\sum_{i=1}^{2 k} \sigma_{i}(H) t^{i}\right)
$$

By a straightforward computation shown in [Chacón 2000] and [Brito et al. 2004], we have $\sigma_{i}(H)=\eta_{i}$ for all $i \in\{1, \ldots, 2 k\}$, where

$$
\eta_{i}=\left\{\begin{array}{cl}
\left(\begin{array}{c}
k \\
i / 2
\end{array}\right) & \text { if } i \text { is even } \\
0 & \text { if } i \text { is odd }
\end{array}\right.
$$

We know that the vector fields $\vec{v}$ and $H$ are the same on $\partial K$. Thus, $\varphi_{t}^{\vec{v}}(K)$ and $\varphi_{t}^{H}(K)$ are $(2 k+1)$-submanifolds of $\mathbb{S}^{2 k+1}\left(\sqrt{1+t^{2}}\right)$ with the same boundary. We 
claim that $\varphi_{t}^{\vec{v}}(K)=\varphi_{t}^{H}(K)$ for all $t$ sufficiently small. In fact, if $p$ is an interior point of $K$,

$$
\lim _{t \rightarrow 0} \varphi_{t}^{\vec{v}}(p)=\lim _{t \rightarrow 0} \varphi_{t}^{H}(p)=p
$$

and then we have necessarily

$$
\varphi_{t}^{\vec{v}}(K)=\varphi_{t}^{H}(K)
$$

for all $t$ sufficiently small; equivalently,

$$
\int_{K} \sqrt{1+t^{2}}\left(1+\sum_{i=1}^{2 k} \sigma_{i}(\vec{v}) t^{i}\right)=\int_{K} \sqrt{1+t^{2}}\left(1+\sum_{i=1}^{2 k} \eta_{i} t^{i}\right)
$$

for all $t>0$ sufficiently small. Consequently, after canceling the factor $\sqrt{1+t^{2}}$ and rearranging the terms, we obtain

$$
\left(\int_{K}\left[\sigma_{1}(\vec{v})-\eta_{1}\right]\right) t+\left(\int_{K}\left[\sigma_{2}(\vec{v})-\eta_{2}\right]\right) t^{2}+\ldots+\left(\int_{K}\left[\sigma_{2 k}(\vec{v})-\eta_{2 k}\right]\right) t^{2 k}=0
$$

for all sufficiently small $t$. By identity of polynomials, we conclude

$$
\int_{K} \sigma_{i}(\vec{v})=\int_{K} \eta_{i}=\eta_{i} \operatorname{vol} K \quad \text { for } i \in\{1, \ldots, 2 k\} .
$$

Using this (for $i=2$ ) together with (3), we get

$$
\mathscr{E}(\vec{v}) \geq \frac{2 k+1}{2} \operatorname{vol} K+\frac{\eta_{2}}{2 k-1} \operatorname{vol} K=\left(\frac{2 k+1}{2}+\frac{k}{2 k-1}\right) \operatorname{vol} K .
$$

We can obtain an analogue of this result for volumes using the following inequality (see [Brito et al. 2004] or [Chacón 2000, page 59]):

$$
\operatorname{vol} \vec{v} \geq \int_{K}\left(1+\sum_{i=1}^{k} \frac{\left(\begin{array}{l}
k \\
i
\end{array}\right)}{\left(\begin{array}{l}
2 k \\
2 i
\end{array}\right)} \sigma_{2 i}(\vec{v})\right) .
$$

But $\int_{K} \sigma_{2 i}=\int_{K} \eta_{2 i}=\eta_{2 i}$ vol $K$ for all $i \in\{1, \ldots, k\}$. Then, we have

$$
\operatorname{vol} \vec{v} \geq\left(1+\sum_{i=1}^{k} \frac{\left(\begin{array}{c}
k \\
i
\end{array}\right)^{2}}{\left(\begin{array}{c}
2 k \\
2 i
\end{array}\right)}\right) \text { vol } K \geq \frac{4^{k}}{\left(\begin{array}{c}
2 k \\
k
\end{array}\right)} \operatorname{vol} K
$$

\section{Final remarks}

(1) If $K$ is a spherical cap (the closure of a connected open set with round boundary of the three unit sphere), the theorem provides a "boundary version" for 
the minimalization theorem of energy and volume functionals on [Brito 2000] and [Gluck and Ziller 1986].

(2) The "Hopf boundary" hypothesis is essential. In fact, if there is no constraint for the unit vector field $\vec{v}$ on $\partial K$, it is possible to construct vector fields on "small caps" such that $\|\nabla \vec{v}\|$ is small on $K$ (exponential maps may be used on that construction). A consequence of this is that $\mathscr{E}(\vec{v})$ and vol $\vec{v}$ are less than volume and energy of Hopf vector fields respectively.

\section{Acknowledgements}

We express our gratitude to Prof. Jaime Ripoll for helpful conversation concerning the final draft of our paper.

\section{References}

[Asimov 1978] D. Asimov, "Average Gaussian curvature of leaves of foliations”, Bull. Amer. Math. Soc. 84:1 (1978), 131-133. MR 0464257 (57 \#4191)

[Borrelli and Gil-Medrano 2006] V. Borrelli and O. Gil-Medrano, "A critical radius for unit Hopf vector fields on spheres”, Math. Ann. 334:4 (2006), 731-751. MR 2209254 (2007a:53070)

[Brito 2000] F. G. B. Brito, "Total bending of flows with mean curvature correction", Differential Geom. Appl. 12:2 (2000), 157-163. MR 1758847 (2001g:53065)

[Brito et al. 1981] F. Brito, R. Langevin, and H. Rosenberg, "Intégrales de courbure sur des variétés feuilletées”, J. Differential Geom. 16:1 (1981), 19-50. MR 633622 (83a:57032)

[Brito et al. 2004] F. B. Brito, P. M. Chacón, and A. M. Naveira, "On the volume of unit vector fields on spaces of constant sectional curvature", Comment. Math. Helv. 79:2 (2004), 300-316. MR 2059434 (2005f:53042)

[Chacón 2000] P. M. Chacón, Sobre a energia e energia corrigida de campos unitários e distribuições. Volume de campos unitários, $\mathrm{PhD}$ thesis, Universidade de São Paulo, 2000.

[Chacón et al. 2001] P. M. Chacón, A. M. Naveira, and J. M. Weston, "On the energy of distributions, with application to the quaternionic Hopf fibrations", Monatsh. Math. 133:4 (2001), 281-294. MR 1915876 (2003k:53050)

[Gluck and Ziller 1986] H. Gluck and W. Ziller, "On the volume of a unit vector field on the threesphere”, Comment. Math. Helv. 61:2 (1986), 177-192. MR 856085 (87j:53063)

[Milnor 1978] J. Milnor, "Analytic proofs of the "hairy ball theorem" and the Brouwer fixed-point theorem”, Amer. Math. Monthly 85:7 (1978), 521-524. MR 505523 (80m:55001)

Received April 20, 2011. Revised April 20, 2012.

FABIANO G. B. BRITO

DePartamento de Matemática e Estatística

UniVERSIDADE FEDERAL Do ESTADo do Rio DE JANEIRO

22290-240 RIO DE JANEIRO RJ

BRAZIL

brifabiano@gmail.com 
ANDRÉ O. GOMES

Instituto DE MATEMÁtica e Estatística

UNIVERSIDADE DE SÃo PAULO

05508-090 SÃo PAULO SP

BRAZIL

gomes@ime.usp.br

Giovanni S. NunES

Instituto DE FísicA E MATEMÁtica

Universidade Federal de Pelotas

96001-970 PELOTAS RS

BRAZIL

giovanni.nunes@ufpel.edu.br 


\title{
PACIFIC JOURNAL OF MATHEMATICS
}

\author{
http://pacificmath.org \\ Founded in 1951 by \\ E. F. Beckenbach (1906-1982) and F. Wolf (1904-1989)
}

\section{EDITORS}

V. S. Varadarajan (Managing Editor)

Department of Mathematics

University of California

Los Angeles, CA 90095-1555

pacific@math.ucla.edu

Vyjayanthi Chari

Department of Mathematics

University of California

Riverside, CA 92521-0135

chari@math.ucr.edu

\section{Robert Finn}

Department of Mathematics Stanford University

Stanford, CA 94305-2125

finn@math.stanford.edu

Kefeng Liu

Department of Mathematics

University of California

Los Angeles, CA 90095-1555

liu@math.ucla.edu
Darren Long

Department of Mathematics

University of California

Santa Barbara, CA 93106-3080

long@math.ucsb.edu

Jiang-Hua Lu

Department of Mathematics

The University of Hong Kong

Pokfulam Rd., Hong Kong jhlu@maths.hku.hk

Alexander Merkurjev

Department of Mathematics

University of California

Los Angeles, CA 90095-1555

merkurev@math.ucla.edu
Sorin Popa

Department of Mathematics University of California

Los Angeles, CA 90095-1555 popa@math.ucla.edu

Jie Qing

Department of Mathematics

University of California

Santa Cruz, CA 95064

qing@cats.ucsc.edu

Jonathan Rogawski

Department of Mathematics

University of California

Los Angeles, CA 90095-1555

jonr@math.ucla.edu

\section{PRODUCTION}

pacific@math.berkeley.edu

\section{SUPPORTING INSTITUTIONS}

ACADEMIA SINICA, TAIPEI

CALIFORNIA INST. OF TECHNOLOGY INST. DE MATEMÁTICA PURA E APLICADA KEIO UNIVERSITY

MATH. SCIENCES RESEARCH INSTITUTE NEW MEXICO STATE UNIV.

OREGON STATE UNIV.

\author{
STANFORD UNIVERSITY \\ UNIV. OF BRITISH COLUMBIA \\ UNIV. OF CALIFORNIA, BERKELEY \\ UNIV. OF CALIFORNIA, DAVIS \\ UNIV. OF CALIFORNIA, LOS ANGELES \\ UNIV. OF CALIFORNIA, RIVERSIDE \\ UNIV. OF CALIFORNIA, SAN DIEGO \\ UNIV. OF CALIF., SANTA BARBARA
}

\author{
UNIV. OF CALIF., SANTA CRUZ \\ UNIV. OF MONTANA \\ UNIV. OF OREGON \\ UNIV. OF SOUTHERN CALIFORNIA \\ UNIV. OF UTAH \\ UNIV. OF WASHINGTON \\ WASHINGTON STATE UNIVERSITY
}

These supporting institutions contribute to the cost of publication of this Journal, but they are not owners or publishers and have no responsibility for its contents or policies.

See inside back cover or pacificmath.org for submission instructions.

The subscription price for 2012 is US \$420/year for the electronic version, and \$485/year for print and electronic.

Subscriptions, requests for back issues from the last three years and changes of subscribers address should be sent to Pacific Journal of Mathematics, P.O. Box 4163, Berkeley, CA 94704-0163, U.S.A. Prior back issues are obtainable from Periodicals Service Company, 11 Main Street, Germantown, NY 12526-5635. The Pacific Journal of Mathematics is indexed by Mathematical Reviews, Zentralblatt MATH, PASCAL CNRS Index, Referativnyi Zhurnal, Current Mathematical Publications and the Science Citation Index.

The Pacific Journal of Mathematics (ISSN 0030-8730) at the University of California, c/o Department of Mathematics, 969 Evans Hall, Berkeley, CA 94720-3840, is published monthly except July and August. Periodical rate postage paid at Berkeley, CA 94704, and additional mailing offices. POSTMASTER: send address changes to Pacific Journal of Mathematics, P.O. Box 4163, Berkeley, CA 94704-0163.

PJM peer review and production are managed by EditFLOW ${ }^{\mathrm{TM}}$ from Mathematical Sciences Publishers.

PUBLISHED BY PACIFIC JOURNAL OF MATHEMATICS

at the University of California, Berkeley 94720-3840

A NON-PROFIT CORPORATION

Typeset in LATEX

Copyright $(02012$ by Pacific Journal of Mathematics 


\section{PACIFIC JOURNAL OF MATHEMATICS}

Volume $257 \quad$ No. $1 \quad$ May 2012

Energy and volume of vector fields on spherical domains

FABiano G. B. BRito, ANDRÉ O. Gomes and Giovanni S. Nunes

Maps on 3-manifolds given by surgery

BOLDIZSÁR KALMÁR and ANDRÁS I. STIPSICZ

Strong solutions to the compressible liquid crystal system

Yu-Ming ChU, Xian-Gao LiU and XIAO LIU

Presentations for the higher-dimensional Thompson groups $n V$

Johanna HenNig and FranCESCo MatuCCI

Resonant solutions and turning points in an elliptic problem with oscillatory

boundary conditions

ALFONSO CASTRO and ROSA PARDO

Relative measure homology and continuous bounded cohomology of topological pairs

\section{Roberto Frigerio and CRISTINA PAgLiAnTINi}

Normal enveloping algebras

ALEXANDRE N. GrishKov, Marina RASSKazova and SALVATORE SICILIANO

Bounded and unbounded capillary surfaces in a cusp domain

YASUNORI AOKI and DAVID SIEGEL

On orthogonal polynomials with respect to certain discrete Sobolev inner product

Francisco Marcellán, Ramadan Zejnullahu, Bujar Fejzullahu and EDMUNDO HUERTAS

Green versus Lempert functions: A minimal example

PASCAL THOMAS

Differential Harnack inequalities for nonlinear heat equations with potentials under the Ricci flow

JIA-YONG WU

On overtwisted, right-veering open books

PAOLO LISCA

Weakly Krull domains and the composite numerical semigroup ring $D+E\left[\Gamma^{*}\right]$

JUNG WOOK LIM

Arithmeticity of complex hyperbolic triangle groups 